\title{
REBOA as a New Damage Control Component in Hemodynamically Unstable Noncompressible Torso Hemorrhage Patients
}

\section{EI REBOA como nuevo actor en el control de daños del paciente hemodinámicamente inestable con hemorragia no compresible del torso}

\author{
Carlos A. Ordoñez ${ }^{1,2,3}$ Michael W. Parra ${ }^{4}$ Yaset Caicedo ${ }^{5}$ Natalia Padilla ${ }^{5}$

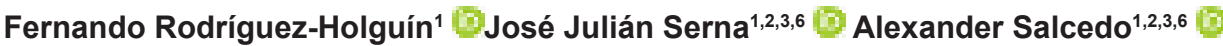 \\ Alberto García ${ }^{1,2,3}$ Claudia Orlas ${ }^{7,8}$ Luis Fernando Pino ${ }^{2,6}$ - Ana Milena del Valle ${ }^{9}$ \\ David Mejia ${ }^{10,11}$ Juan Carlos Salamea-Molina ${ }^{12,13}$ Megan Brenner ${ }^{14}$ Tal Hörer ${ }^{15}$ \\ ordonezcarlosa@gmail.com, carlos.ordonez@fvl.org.co
}

\section{OPEN ACCESS}

Citation: Ordoñez CA, Parra MW, Caicedo Y, Padilla N, Rodríguez HF, Serna JJ, Salcedo A, García A, Orlas C, Pino LF, Del Valle AM, Mejía D, Salamea MJC, Brenner M, Hörer T. REBOA as a New Damage Control Component in emodynamically Unstable Noncompressible Torso Hemorrhage Patients. Colomb Med (Cali). 2020; 51(4):e-2014506

http://doi.org/10.25100/ cm.v51i 4.4506

Received : 20 Aug 2020

Revised : 15 Oct 2020

Accepted : 09 Dec 2020

Published: 29 Dec 2020

Keywords:

Resuscitative endovascular balloon occlusion of the aorta; damage control; noncompressible torso hemorrhage; hemodynamically unstable; wounds; gunshot; injury severity score; trauma centers; REBOA; advanced trauma life support care; balloon occlusion; nonpenetrating; endovascular procedures.

Palabras clave:

Balón de resucitación endovascular de oclusión aórtica; control de daños; hemorragia no compresible del torso; hemodinámicamente inestable; heridas penetrantes; puntuación de gravedad de la lesión; centros de trauma; atención de soporte vital avanzado para traumatismos; heridas no penetrantes; procedimientos endovasculares; REBOA
1 Fundación Valle del Lili, Division of Trauma and Acute Care Surgery, Department of Surgery. Cali, Colombia. 2 Universidad del Valle, Facultad de Salud, Escuela de Medicina, Division of Trauma and Acute Care Surgery, Department of Surgery. Cali, Colombia.3 Universidad Icesi, Cali, Colombia. 4 Broward General Level I Trauma Center, Department of Trauma Critical Care, Fort Lauderdale, FL - USA, 5 Fundación Valle del Lili, Centro de Investigaciones Clínicas (CIC), Cali, Colombia, 6 Hospital Universitario del Valle, Division of Trauma and Acute Care Surgery, Department of Surgery. Cali, Colombia.7 Center for Surgery and Public Health, Department of Surgery, Brigham \& Women's Hospital, Boston, USA.8 Harvard Medical School \& Harvard T.H. Chan School of Public Health, Boston, USA.9 Hospital Felix Bulness, Division of Surgery, Santiago de Chile, Chile.10 Hospital Pablo Tobon Uribe, Department of Surgery, Medellin, Colombia.11 Universidad de Antioquia, Department of Surgery, Medellin, Colombia. 12 Hospital Vicente Corral Moscoso, Division of Trauma and Acute Care Surgery. Cuenca, Ecuador., 13 Universidad del Azuay, Escuela de Medicina. Cuenca, Ecuador.14 University of California, Department of Surgery Riverside University Health Systems. Riverside, CA, USA.15 Örebro University Hospital, Faculty of Medicine, Department of Cardiothoracic and Vascular Surgery, Örebro, Sweden.

\section{Abstract}

Noncompressible torso hemorrhage is one of the leading causes of preventable death worldwide. An efficient and appropriate evaluation of the trauma patient with ongoing hemorrhage is essential to avoid the development of the lethal diamond (hypothermia, coagulopathy, hypocalcemia, and acidosis). Currently, the initial management strategies include permissive hypotension, hemostatic resuscitation, and damage control surgery. However, recent advances in technology have opened the doors to a wide variety of endovascular techniques that achieve these goals with minimal morbidity and limited access. An example of such advances has been the introduction of the Resuscitative Endovascular Balloon Occlusion of the Aorta (REBOA), which has received great interest among trauma surgeons around the world due to its potential and versatility in areas such as trauma, gynecology \& obstetrics and gastroenterology. This article aims to describe the experience earned in the use of REBOA in noncompressible torso hemorrhage patients. Our results show that REBOA can be used as a new component in the damage control resuscitation of the severely injured trauma patient. 
Copyright: @ 2020 Universidad del Valle.

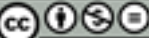

Conflict of Interest: None

Corresponding author:

Carlos A. Ordonez, MD, FACS. Division of Trauma and Acute Care Surgery, Department of Surgery. Fundación Valle del Lili. Cali, Colombia; Division of Trauma and Acute Care Surgery, Department of Surgery, Universidad del Valle, Cali, Colombia; Universidad Icesi, Cali, Colombia. Email: ordonezcarlosa@ gmail.com, carlos.ordonez@fvl.org.co
To this end, we propose two new deployment algorithms for hemodynamically unstable noncompressible torso hemorrhage patients: one for blunt and another for penetrating trauma. We acknowledge that REBOA has its limitations, which include a steep learning curve, its inherent cost and availability. Although to reach the best outcomes with this new technology, it must be used in the right way, by the right surgeon with the right training and to the right patient.

\section{Resumen}

La hemorragia no compresible del torso es una de las principales causas de muerte prevenibles alrededor del mundo. Una evaluación eficiente y apropiada del paciente traumatizado con hemorragia activa es la esencia para evitar el desarrollo del rombo de la muerte (hipotermia, coagulopatía, hipocalcemia y acidosis). Actualmente, las estrategias de manejo inicial incluyen hipotensión permisiva, resucitación hemostática y cirugía de control de daños. Sin embargo, los recientes avances tecnológicos han abierto las puertas a una amplia variedad de técnicas endovasculares que logran esos objetivos con una morbilidad mínima y un acceso limitado. Un ejemplo de estos avances ha sido la introducción del balón de resucitación de oclusión aortica; REBOA (Resuscitative Endovascular Balloon Occlusion of the Aorta , por sus sigla en inglés ), el cual, ha tenido gran provecho entre los cirujanos de trauma alrededor del mundo debido a su potencial y versatilidad en áreas como trauma, ginecología y obstetricia, y gastroenterología. El objetivo de este artículo es describir la experiencia lograda en el uso del REBOA en pacientes con hemorragia no compresible del torso. Nuestros resultados muestran que el REBOA puede usarse como un nuevo actor en la resucitación de control de daños del paciente con trauma severo, para este fin, nosotros proponemos dos nuevos algoritmos para el manejo de pacientes hemodinámicamente inestables: uno para trauma cerrado y otro para trauma penetrante. Se reconoce que el REBOA tiene sus limitaciones, las cuales incluye un periodo de aprendizaje, su costo inherente y la disponibilidad. A pesar de esto, para lograr los mejores resultados con esta nueva tecnología, el REBOA debe ser usado en el momento correcto, por el cirujano correcto con el entrenamiento y el paciente correcto.

\section{Remark}

\section{1)Why was this study conducted?}

This article aims to describe the experience earned in the use of REBOA in non-compressible torso hemorrhage patients by Trauma and Emergency Surgery Group (CTE) of Cali, Colombia.

\section{2) What were the most relevant results of the study?}

We propose two new deployment algorithms for hemodynamically unstable noncompressible torso hemorrhage patients: one for blunt and another for penetrating trauma. REBOA must be used in the right way, by the right surgeon with the right training and to the right patient.

\section{3) What do these results contribute?}

Our results show that REBOA can be used as a new component in the damage control resuscitation of the severely injured trauma patient 


\section{Introduction}

Noncompressible torso hemorrhage is one of the leading causes of preventable death worldwide ${ }^{1}$. An efficient and appropriate evaluation of the trauma patient with ongoing hemorrhage is essential to avoid developing the lethal diamond (hypothermia, coagulopathy, hypocalcemia, and acidosis) ${ }^{2,3}$. The initial management strategies include permissive hypotension, hemostatic resuscitation, and damage control surgery ${ }^{4}$. However, recent advances in technology have opened the doors to a wide variety of endovascular techniques that achieve these goals with minimal morbidity and limited access ${ }^{5-7}$. An example of such advances has been the introduction of the Resuscitative Endovascular Balloon Occlusion of the Aorta (REBOA), which has received significant interest among trauma surgeons worldwide due to its potential and versatility in areas such as trauma, gynecology \& obstetrics and gastroenterology ${ }^{8}$. This article aims to describe the experience earned in the use of REBOA in Noncompressible torso hemorrhage patients.

This article is a consensus that synthesizes the experience earned during the past 30 years in trauma critical care management of the severely injured patient from the Trauma and Emergency Surgery Group (CTE) of Cali, Colombia, which is made up of experts from the University Hospital Fundación Valle del Lili, the University Hospital del Valle "Evaristo García" the Universidad del Valle and Universidad Icesi, the Asociación Colombiana de Cirugia, the Pan-American Trauma Society and the collaboration of national and international specialists of the United States of America, Europe, and Latin America.

\section{Materials and Methods}

A prospective, observational, single-center study was performed of all patients (age $>14$ years old) who underwent an endovascular aortic occlusion from January 2015 to December 2019 at our Level I University-affiliated Trauma Center in Cali, Colombia: Fundación Valle del Lili (FVL).

Patient demographics, clinical course, procedural conditions, and clinical outcomes data were collected and recorded from our FVL-REBOA Registry. The study was approved by our institutional ethics and review board committee. In practice, when a REBOA was placed, the trauma surgeon would immediately inform the research assistant, who would access all clinical records and extract patient data in real-time. The decision to place a REBOA resided on the treating trauma surgeon, and the most common indication was sustained hypotension (systolic blood pressure $<90 \mathrm{mmHg}$ ) that did not respond to initial resuscitation.

Arterial access was established via the common femoral artery by surgical cutdown or percutaneously by ultrasound guidance. A 7, 11, or 14 Fr introducer sheath was inserted (according to availability). A REBOA catheter was placed in Zone 1 (extends from the origin of the left subclavian artery to the celiac trunk). Balloon inflation was ideally kept less than 30 minutes and reposition to Zone 3 (extends from lowest renal artery to the aortic bifurcation) according to the patient's needs. Partial REBOA was also used according to the patient's response and ultimate control of surgical bleeding. We developed an institutional algorithm to standardize the decision making on behalf of the treating trauma surgeon. The algorithm is instituted on arrival to the emergency room, where Advanced Trauma Life Support (ATLS) principles are followed, and an early arterial vascular access is obtained. The institutional massive transfusion protocol is activated, and an Extended Focused Assessment with Sonography for Trauma (E-FAST) is done. The ultimate decision of transferring the patient to the operating room in cases of ongoing surgical bleeding and non-responders to initial aggressive damage control resuscitation should be undertaken simultaneously with the placement of a REBOA. All the REBOA's were placed by one of three Senior Attending Trauma Surgeon's that had been previously trained and certified in the technique. A rotating 
Trauma Fellow always assisted them. The continuous variables were described by median and interquartile range, the categorical variables by relative and absolute frequency. Statistical analyses were carried out in R-Language 3.5.6.

\section{Results}

A total of 56 patients underwent REBOA placement. Forty-eight (85\%) were male with a median age of 33 (IQR: 23-45) years. Thirty-seven (66\%) suffered penetrating trauma, and of these, $30(81.8 \%)$ were from gunshot wounds, and $7(18.1 \%)$ were from stab wounds. Nineteen (33.9\%) suffered blunt trauma. All patients were hemodynamically unstable upon arrival to the emergency room median systolic blood pressure $=69$ (IQR: 58-88) $\mathrm{mm}$ Hg; median Heart Rate $=110$ (IQR: 96-127) bpm., and ten (17.8\%) had cardiac arrest before or on arrival to the emergency room. The median Injury Severity Score was 25 (IQR: 25-37), median abdominal Abbreviated Injury Score (AIS) was 5 (IQR: 4-5), median chest AIS was 5 (IQR: 3-5), and median pelvic/extremity AIS was 3 (IQR: 3-3). Thoracic vascular injuries were presented in 19 (38\%) patients (5 with subclavian artery injury, 4 with internal mammary artery injury, 4 with subclavian vein injury, among others), 11 (22\%) had abdominal or pelvic vascular injuries (3 with common/external/internal iliac artery injuries, 3 with iliac vein injury, among others). Severe liver trauma [American Association for the Surgery of Trauma (AAST) Grade IV-V] was reported in 9 (18\%), and $6(12 \%)$ had severe lung injury (AAST Grade IV-V) (Table 1).

Ninety-four percent (47 patients) of all REBOA's were placed in the operating room, common femoral artery access was established via surgical cutdown in 46 (82.1\%) cases, and 10 (17.8\%) were done by ultrasound guidance. Our first REBOA's commonly required the placement of 11 to $14 \mathrm{Fr}$ sheaths [36 (64.2\%) patients]. External anatomical landmarks were used to guide its positioning in 55 (98\%) cases; one required C-arm fluoroscopy and none were placed by ultrasound guidance. Median systolic blood pressure pre-aortic occlusion was 50 (IQR: 40-65) $\mathrm{mm} \mathrm{Hg}$ and the median systolic blood pressure post-aortic occlusion was 110 (IQR: 89-123)

Table 1. Baseline characteristics of patients receiving REBOA for treatment of noncompressible torso hemorrhage.

\begin{tabular}{|c|c|}
\hline Variable & REBOA $(n=56)$ \\
\hline Age, median (IQR) & $33(23-45)$ \\
\hline Male sex, $\mathrm{n}(\%)$ & $48(85)$ \\
\hline Penetrating mechanism, n (\%) & $37(66)$ \\
\hline Gunshot wound, n (\%) & $30(81.08)$ \\
\hline Stab wound, n (\%) & 7 (18.92) \\
\hline Blunt mechanism, n (\%) & $19(33.9)$ \\
\hline Injury Severity Score, median (IQR) & $25(25-37)$ \\
\hline Chest AIS, median (IQR) & $5(3-5)$ \\
\hline Abdominal AIS, median (IQR) & $5(4-5)$ \\
\hline Pelvic/extremity AIS, median (IQR) & $3(3-3)$ \\
\hline \multicolumn{2}{|l|}{ Vital Signs } \\
\hline Systolic Blood Pressure, mm HG, mean (SD) & $69(29.1)$ \\
\hline Heart rate, bpm, median (IQR) & $110(96-127)$ \\
\hline Glasgow Coma Score, median (IQR) & $14(10-15)$ \\
\hline Cardiac arrest, $\mathrm{n}(\%)$ & $10(17.8)$ \\
\hline \multicolumn{2}{|l|}{ Resuscitation Requirements } \\
\hline Units of Packed-Red Blood Cells, 6 h, median (IQR) & $6(4-9)$ \\
\hline Units of Fresh Frozen Plasma, 6 h, median (IQR) & $4(3-6)$ \\
\hline Platelets, 6 h, median (IQR) & $6(0-6)$ \\
\hline Cryoprecipitate, 6 h, median (IQR) & $7(0-10)$ \\
\hline Units of Packed-Red Blood Cells, 24 h, median (IQR) & $7(5-12)$ \\
\hline Units of Fresh Frozen Plasma, 24 h, median (IQR) & $7(4-11)$ \\
\hline Platelets, $24 \mathrm{~h}$, median (IQR) & $6(0-12)$ \\
\hline Cryoprecipitate, $24 \mathrm{~h}$, median (IQR) & $10(4-16)$ \\
\hline Crystalloids, $24 \mathrm{~h}$, mean (SD)* & $4,905(2,752)$ \\
\hline
\end{tabular}

AIS: Abbreviated Injury Score, IQR: Interquartile Range, SD: Standard Deviation. 
Table 2. Characteristics related to REBOA placement

\begin{tabular}{|c|c|}
\hline \multirow{2}{*}{$\begin{array}{l}\text { Variable } \\
\text { Arterial access }\end{array}$} & \multirow[t]{2}{*}{ REBOA (n=56) } \\
\hline & \\
\hline Surgical cutdown, n (\%) & $46(82.1)$ \\
\hline Ultrasound-guided percutaneous, n (\%) & $10(17.8)$ \\
\hline \multicolumn{2}{|l|}{ Location } \\
\hline Emergency department, n (\%) & $2(4)$ \\
\hline Operating room, $\mathrm{n}(\%)$ & $53(94)$ \\
\hline Angiography suite, $\mathrm{n}(\%)$ & $1(2)$ \\
\hline \multicolumn{2}{|l|}{ Pre-Aortic Occlusion } \\
\hline systolic blood pressure, mm Hg, median (IQR) & $50(40-65)$ \\
\hline \multicolumn{2}{|l|}{ Post-Aortic Occlusion } \\
\hline systolic blood pressure, mm Hg, median (IQR) & $110(89-123)$ \\
\hline \multicolumn{2}{|l|}{ Positioning zone } \\
\hline Zone $1, \mathrm{n}(\%)$ & $24(42.8)$ \\
\hline Zone $3, \mathrm{n}(\%)$ & $6(10.7)$ \\
\hline Zone 1 + Zone 3, n (\%) & $26(46.2)$ \\
\hline \multicolumn{2}{|l|}{ Duration of Aortic Occlusion } \\
\hline Total occlusion, min, median (IQR) & $41(24-60)$ \\
\hline Zone 1 , min, median (IQR) & $25(19-43)$ \\
\hline Zone 3, min, median (IQR) & $16(10-36)$ \\
\hline \multicolumn{2}{|l|}{ Type of Balloon Catheter } \\
\hline CodaTM, n (\%) & $34(60.7)$ \\
\hline Prytime emergency room-REBOATM, n (\%) & $17(30.3)$ \\
\hline Rescue balloonTM, n (\%) & $3(5.3)$ \\
\hline Jotec balloonTM, n (\%) & $2(3.5)$ \\
\hline \multicolumn{2}{|l|}{ Aortic Occlusion Positioning Technique } \\
\hline C-arm fluoroscopy, n (\%) & $1(2)$ \\
\hline Anatomical Landmarks, n (\%) & $55(98)$ \\
\hline Ultrasound & 0 \\
\hline
\end{tabular}

AO: Aortic Occlusion, IQR: Interquartile Range, REBOA: Resuscitative Endovascular Balloon of the Aorta.

$\mathrm{mm} \mathrm{Hg}$. The median time between the start of the procedure and successful aortic occlusion was 5 (IQR: 5-10) min. REBOA was deployed in Zone 1 exclusively in 24 (42.8\%) cases and was repositioned to Zone 3 in 26 (48.2\%). Overall, the median time of occlusion was 41 (IQR: 24-60) minutes, and those who had exclusive Zone 1 occlusion was 25 (IQR: 19-43) minutes. The only complications related to REBOA placement were those related to vascular access (1 pseudoaneurysm, 2 thromboses, 4 femoral artery dissection, and 1 local infection), and associated adverse systemic events consisted of 2 cases of gastrointestinal bleeding, 2 of bowel ischemia, and 7 of renal failure (Table 2).

In conjunction with the use of REBOA, 10 (17.8\%) patients underwent angioembolization, 40 (72\%) laparotomy, 19 (34\%) sternotomy, and 3 (6\%) thoracotomy. Thoracic damage control surgery was implemented in $15(26.7 \%)$ patients, abdominal damage control surgery in 33 $(58.9 \%)$ and $5(8.9 \%)$ required both. All patients underwent blood product transfusion within the first 6 hours upon admission median packed red blood cells 6 (IQR: 4-9) units; median fresh frozen plasma 4 (IQR: 3-6) units; median platelets 6 [(IQR: 0-6) units]. A total of 13 (26\%) patients required massive transfusion protocol activation at a 1:1:1 ratio (Table 1 ). The median intensive care unit (ICU) length of stay was 7 (IQR: 3-19) days, median hospital length of stay was 11 (IQR: 4-25) days, and the median mechanical ventilation time was 4 (IQR: 2-7) days. The overall in-hospital mortality was $28.5 \%$ (16).

\section{Surgical Rescue of a Hemodynamically Unstable Noncompressible torso hemorrhage Patient using REBOA}

We have devised new algorithms that address in 5 easy to understand steps on how to manage a hemodynamically unstable patient suffering from Noncompressible torso hemorrhage from both blunt (Figure 1) and penetrating trauma (Figure 2): 


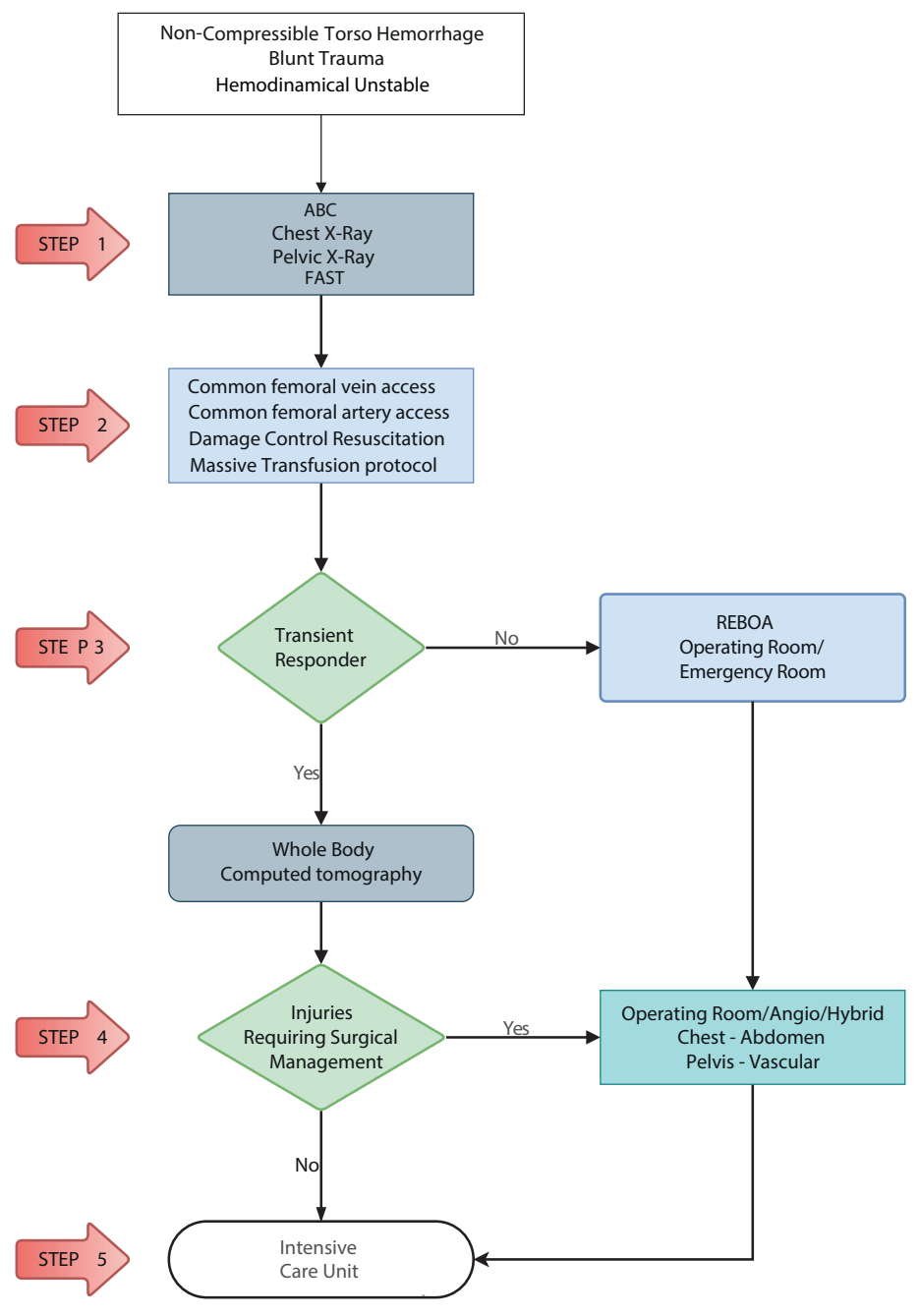

Figure 1. Hemodynamically Unstable Noncompressible torso hemorrhage: Blunt Trauma Algorithm. ABC: Airway, Breathing, Circulation; FAST: Focussed Assesment with Sonography for Trauma; REBOA: Resuscitative Endovascular Balloon Occlusion of the Aorta

\section{Blunt Trauma}

- STEP 1: Attention should be directed towards identifying all immediate life-threatening injuries following the ABC mnemonic of ATLS chest/pelvic x-ray and E-FAST.. All lifethreatening injuries confirmed by initial imaging should be addressed immediately before to continuing to the next step (for example chest tube, pelvic binder/sheet placement).

- STEP 2: Both a common femoral vein and artery lines should be obtained for intravenous access and blood pressure monitoring. An aggressive damage control resuscitation is initiated via the activation of the institution's massive transfusion protocol.

- STEP 3: If the patient is a transient responder, then a whole-body computed tomography is recommended to further delineate the extent of the injuries. If the patient is a nontransient responder, then he or she should undergo REBOA Zone 1 placement either in the emergency room or the operating room.

- STEP 4: Both the transient responder that required whole-body computed tomography with positive surgical findings and the non-transient responder that required REBOA Zone 1 placement, should be transferred immediately to the operating room, angio, and/ or hybrid room for definitive or damage control surgical management. 


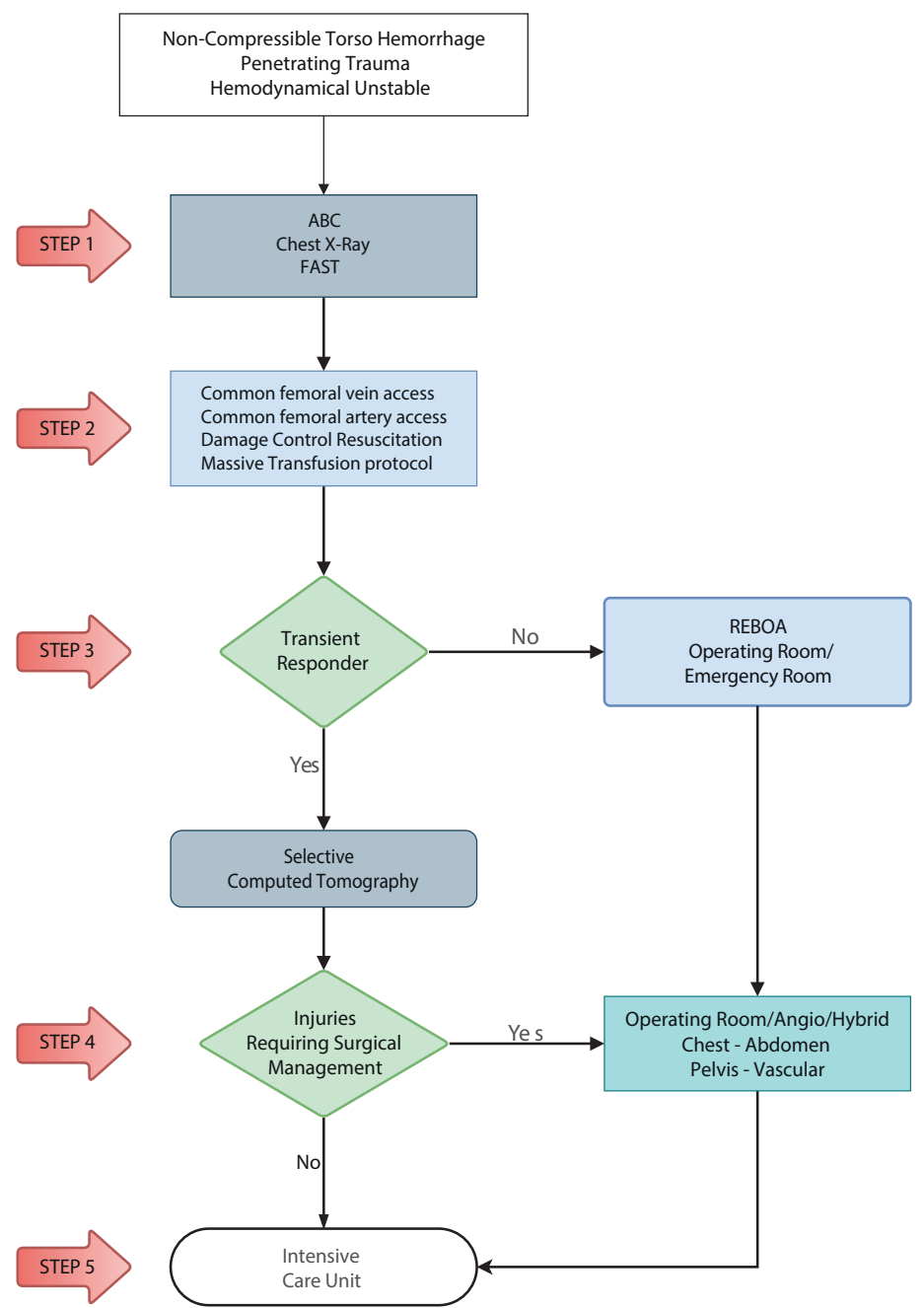

Figure 2. Hemodynamically Unstable Noncompressible torso hemorrhage: Penetrating Trauma Algorithm. ABC: Airway, Breathing, Circulation; FAST: Focussed Assesment with Sonography for Trauma; REBOA: Resuscitative

Endovascular Balloon Occlusion of the Aorta

- STEP 5: All transient responders without surgical injuries on whole-body computed tomography and those that required operating room, angio, and/or hybrid room for definitive or damage control surgical management should be transferred to the ICU for completion of their damage control resuscitation. Those that required damage control surgery should return to the operating room within 24-72 hours for definitive care.

\section{Penetrating Trauma}

- $\quad$ STEP 1: Attention should be directed towards identifying all immediate life-threatening injuries following the ABC mnemonic of ATLS (chest $\mathrm{x}$-ray and FAST). All lifethreatening injuries confirmed by initial imaging should be addressed immediately before the next step (for example chest tube placement).

- $\quad$ STEP 2: Both a common femoral vein and artery lines are placed for intravenous access and blood pressure monitoring. An aggressive damage control resuscitation is initiated via the activation of the institution's massive transfusion protocol. 
- STEP 3: If the patient is a transient responder, then a selective computed tomography (CT) is recommended to further delineate the extent of the injuries. If the patient is a non-transient responder, they should undergo REBOA Zone 1 placement either in the emergency room or the operating room.

- $\quad$ STEP 4: Both the transient responder that required selective CT with positive surgical findings and the non-transient responder that required REBOA Zone 1 placement, should be transferred immediately to the operating room, angio and/or hybrid room for definitive or damage control surgical management.

- STEP 5: All transient responders without surgical injuries on selective CT and those that required operating room, angio, and/or hybrid room for definitive or damage control surgical management should be transferred to the ICU for completion of their damage control resuscitation. Those that required damage control surgery should return to the operating room within 24-72 hours for definitive care.

\section{Discussion}

REBOA is an important resuscitative tool that ultimately prevents hemodynamic collapse while at the same time maintains coronary and cerebral perfusion in hemodynamically unstable trauma patients, and due to its less invasive nature, it has become an alternative to resuscitative thoracotomy ${ }^{9-16}$. Hörer et al. proposed the concept of Endovascular Resuscitation and Trauma Management, a vision that integrates a multidisciplinary patient-centered approach that achieves prompt and effective hemorrhage control with significantly less surgical insult ${ }^{6,17}$. We implemented our institutional use of REBOA in 2014 and became pioneers in Latin America on its use, developing new indications to the traditional uses described by

\section{ATLS}

$\mathrm{ABCDE}+$ common femoral artery access

Damage Control Resuscitation sustained hypotension (systolic blood pressure $<90 \mathrm{mmHg}$ )

\section{4}

4

(1)


U.S.A. and European counterparts ${ }^{18-20}$. This is partly due to the increased rate of penetrating trauma (68\%) that plagues our Colombian society, which is far higher than that of similar published series of 7 to $15 \%$ worldwide ${ }^{21,22}$. Also, our patients commonly arrive in severe hemorrhagic shock with a high associated Injury Severity Score $(>25)$ which has made us push the envelope on its use and venture into applying it even in cases of penetrating thoracic trauma with excellent results ${ }^{8}$. In addition, we have created a novel two-team approach to caring for the critically ill trauma patient which allows one team to perform surgical exposures and definitive hemorrhage control, while the other team simultaneously manages the resuscitation including all aspects of REBOA. All REBOA catheters were placed by the attending trauma surgeon and the arterial access was obtained via a cutdown technique utilizing anatomical landmarks in most cases. Another striking difference is that most of our REBOA's are placed in the operating room (94\%) and not in the emergency room, which is the norm worldwide ${ }^{23,24}$. All of our REBOA's are inflated initially in Zone 1 of the aorta and subsequently lowered to Zone 3 when indicated. Our initial experience began with the use of large introducer sheaths (11-14 Fr) (36 patients) which caused, as to be expected, multiple site-related complications (8 patients) requiring open surgical repair ${ }^{25}$. But with the introduction of the newly designed $7 \mathrm{Fr}$ catheters, these vascular access complications have resolved. Their use is our recommendation at any center that is contemplating the adoption of this technology $24,26,27$.

Noncompressible torso hemorrhage patients require immediate control of ongoing surgical hemorrhage and with this goal in mind we have developed at our institution two separate management algorithms: one for blunt and another for penetrating trauma. These algorithms should be carried out by two different teams that work simultaneously. One performs the actual surgical procedure required to achieve Noncompressible torso hemorrhage control, and the other places and inflates the REBOA. As a result, the placement of a REBOA does not entail any surgical delay in obtaining definitive control of the primary source of hemorrhage and does not oppose the concept of damage control surgery. To the contrary, we believe that REBOA is a new and vital pillar of Damage Control Resuscitation. These algorithms are centered according to the following conceptual axis (Figure 3):

- Instead of the traditional "ABCDE" mnemonic advocated by ATLS we should follow Hörer's modification "AABCDE" where the second "A" represents early common femoral artery access via placement of a vascular sheath ${ }^{6,28}$.

- REBOA placement requires a well-trained surgeon ${ }^{8}$.

- REBOA is a dynamic tool that demands exclusive attention on behalf of the surgeon for its ongoing management. The different techniques of its use (complete versus partial) and sequential deployment from Zone 1 to Zone 3 should be directed by the treating surgeon with the aim of achieving hemorrhage control while at the same time decreasing the possibility of collateral damage $e^{29,30}$.

- REBOA is an essential pillar of damage control resuscitation in the hemodynamically unstable Noncompressible torso hemorrhage trauma patient. REBOA should be placed when the patient is hemodynamically unstable (systolic blood pressure $<90 \mathrm{~mm} \mathrm{Hg}$ ) and not when the patient develops cardiac arrest which was until recently the classic indication for a resuscitative left thoracotomy ${ }^{31,32}$.

REBOA has the potential to evolve into the newest member of the diverse trauma team involved in the care of the severely injured. As all new technologies, its effectiveness is limited by its human counterpart. As the trauma surgeon improves in its use and placement, it is only then that the REBOA can establish a strong foothold in the management of these patients. 


\section{Conclusion}

Our results show that REBOA can be used as a new pillar in the damage control resuscitation of the severely injured trauma patient and to this end we propose two new deployment algorithms for hemodynamically unstable Noncompressible torso hemorrhage patients: one for blunt and another for penetrating trauma. We acknowledge that REBOA has its limitations which include a steep learning curve, its inherent cost and availability. Although, to reach the best outcomes with this new technology, it must be used in the right way, by the right surgeon with the right training and to the right patient.

\section{References}

1. White JM, Stannard A, Burkhardt GE, Eastridge BJ, Blackbourne LH, Rasmussen TE. The epidemiology of vascular injury in the wars in Iraq and Afghanistan. Ann Surg 2011;253:1184-9. Doi: 10.1097/

SLA.0b013e31820752e3.

2. Moore FA, McKinley BA, Moore EE. The next generation in shock resuscitation. Lancet 2004;363:1988-96. Doi: 10.1016/S0140-6736(04)16415-5.

3. Ditzel RM, Anderson JL, Eisenhart WJ, Rankin CJ, DeFeo DR, Oak S, et al. A review of transfusion- And trauma-induced hypocalcemia: Is it time to change the lethal triad to the lethal diamond? J Trauma Acute Care Surg 2020;88:434-9. Doi: 10.1097/TA.0000000000002570.

4. Stawicki SP, Brooks A, Bilski T, Scaff D, Gupta R, Schwab CW, et al. The concept of damage control: Extending the paradigm to emergency general surgery. Injury 2008;39:93-101. Doi: 10.1016/j.injury.2007.06.011.

5. Hörer TM, Skoog P, Pirouzram A, Nilsson KF, Larzon T. A small case series of aortic balloon occlusion in trauma: lessons learned from its use in ruptured abdominal aortic aneurysms and a brief review. Eur J Trauma Emerg Surg 2016;42:585-92. Doi: 10.1007/s00068-015-0574-0.

6. Hörer T, Pirouzram A, Khan M, Brenner M, Cotton B, Duchesne J. Endovascular Resuscitation and Trauma Management (EVTM) - Practical Aspects and Implementation. Shock. 2020. doi: 10.1097/ SHK.0000000000001529

7. Du Bose JJ, Scalea TM, Brenner M, Skiada D, Inaba K, Cannon J, et al. The AAST prospective Aortic Occlusion for Resuscitation in Trauma and Acute Care Surgery (AORTA) registry: Data on contemporary utilization and outcomes of aortic occlusion and resuscitative balloon occlusion of the aorta (REBOA). J Trauma Acute Care Surg. 2016;81(3):409-19 Doi: 10.1097/TA.0000000000001079.

8. Ordoñez CA, Rodríguez F, Parra M, Herrera JP, Guzmán-Rodríguez M, Orlas C, et al. Resuscitative endovascular balloon of the aorta is feasible in penetrating chest trauma with major hemorrhage: Proposal of a new institutional deployment algorithm. J Trauma Acute Care Surg 2020;89:311-9. Doi: 10.1097/ ta. 0000000000002773 .

9. Faulconer ER, Branco BC, Loja MN, Grayson K, Sampson J, Fabian TC, et al. Use of open and endovascular surgical techniques to manage vascular injuries in the trauma setting: A review of the American Association for the Surgery of Trauma PROspective Observational Vascular Injury Trial registry. J Trauma Acute Care Surg 2018;84:411-7. Doi: 10.1097/TA.0000000000001776.

10. Stannard A, Eliason JL, Rasmussen TE. Resuscitative endovascular balloon occlusion of the aorta (REBOA) as an adjunct for hemorrhagic shock. J Trauma - Inj Infect Crit Care 2011;71:1869-72. Doi: 10.1097/ TA.0b013e31823fe90c.

11. Meléndez JJ, Ordóñez CA, Parra MW, Orlas CP, Manzano-Núñez R, García AF, et al. Balón de reanimación endovascular de aorta para pacientes en riesgo de o en choque hemorrágico: experiencia en un centro de trauma de Latinoamérica. Rev Colomb Cirugía 2019;34:124-31. Doi: 10.30944/20117582.106. 
12. Manzano Nunez R, Naranjo MP, Foianini E, Ferrada P, Rincon E, García-Perdomo HA, et al. A metaanalysis of resuscitative endovascular balloon occlusion of the aorta (REBOA) or open aortic cross-clamping by resuscitative thoracotomy in noncompressible torso hemorrhage patients. World J Emerg Surg 2017;12:30. Doi: 10.1186/s13017-017-0142-5.

13. McGreevy DT, Abu-Zidan FM, Sadeghi M, Pirouzram A, Toivola A, Skoog P, et al. Feasibility and Clinical Outcome of Reboa in Patients with Impending Traumatic Cardiac Arrest. Shock. 2019; 54(2):218-223. Doi: 10.1097/SHK.0000000000001500.

14. Beyer CA, Hoareau GL, Tibbits EM, Davidson AJ, DeSoucy ED, Simon MA, et al. Resuscitative endovascular balloon occlusion of the aorta induced myocardial injury is mitigated by endovascular variable aortic control. J Trauma Acute Care Surg 2019;87:590-8. Doi: 10.1097/TA.0000000000002363.

15. Tibbits EM, Hoareau GL, Simon MA, Davidson AJ, DeSoucy ES, Faulconer ER, et al. Location is everything: The hemodynamic effects of REBOA in Zone 1 versus Zone 3 of the aorta. J Trauma Acute Care Surg 2018;85:101-7. Doi: 10.1097/TA.0000000000001858.

16. Yamashiro KJ, Wishy AM, Beyer CA, Kashtan HW, Galganski LA, Grayson JK, et al. Resuscitative endovascular balloon occlusion of the aorta (REBOA) in a pediatric swine liver injury model: A pilot study. $J$ Pediatr Surg 2020;55:346-52. Doi: 10.1016/j.jpedsurg.2019.10.013.

17. Wikström MB, Krantz J, Hörer TM, Nilsson KF. Resuscitative endovascular balloon occlusion of the inferior vena cava is made hemodynamically possible by concomitant endovascular balloon occlusion of the aorta-A porcine study. J Trauma Acute Care Surg 2020;88:160-8. Doi: 10.1097/TA.0000000000002467.

18. García AF, Manzano-Nunez R, Orlas CP, Ruiz-Yucuma J, Londoño A, Salazar C, et al. Association of resuscitative endovascular balloon occlusion of the aorta (REBOA) and mortality in penetrating trauma patients. Eur J Trauma Emerg Surg 2020:10.1007/s00068-020-01370-9. Doi: 10.1007/s00068-020-01370-9.

19. Manzano-Nunez R, Escobar-Vidarte MF, Naranjo MP, Rodriguez F, Ferrada P, Casallas JD, et al. Expanding the field of acute care surgery: a systematic review of the use of resuscitative endovascular balloon occlusion of the aorta (REBOA) in cases of morbidly adherent placenta. Eur J Trauma Emerg Surg 2018;44:519-26. Doi: 10.1007/s00068-017-0840-4.

20. Ordoñez CA, Parra MW, Manzano-Nunez R, Herrera-Escobar JP, Serna JJ, Rodriguez Ossa P, et al. Intraoperative combination of resuscitative endovascular balloon occlusion of the aorta and a median sternotomy in hemodynamically unstable patients with penetrating chest trauma: Is this feasible? J Trauma Acute Care Surg 2018;84:752-7. Doi: 10.1097/TA.0000000000001807.

21. Brenner M, Moore L, Teeter W, Hu P, Yang S, Wasicek P, et al. Exclusive clinical experience with a lower profile device for resuscitative endovascular balloon occlusion of the aorta (REBOA). Am J Surg 2019;217:1126-9. Doi: 10.1016/j.amjsurg.2018.11.029.

22. Joseph B, Zeeshan M, Sakran J V, Hamidi M, Kulvatunyou N, Khan M, et al. Nationwide Analysis of Resuscitative Endovascular Balloon Occlusion of the Aorta in Civilian Trauma. JAMA Surg 2019;154:500-8. Doi: 10.1001/jamasurg.2019.0096.

23. Cannon JW, Khan MA, Raja AS, Cohen MJ, Como JJ, Cotton BA, et al. Damage control resuscitation in patients with severe traumatic hemorrhage: A practice management guideline from the Eastern Association for the Surgery of Trauma. J Trauma Acute Care Surg. 2017; 82: 605-17. Doi: 10.1097/TA.0000000000001333.

24. Ryan G, Swift K, Williamson F, Scriven E, Zheng O, Eley R. Feasibility of reboa-resuscitative endovascular balloon occlusion of the aorta-in trauma-related noncompressible torso hemorrhage at two metropolitan trauma centers. Ochsner J 2018;18:201-3. Doi: 10.31486/toj.18.0025. 
25. Ordoñez CA, Khan M, Cotton B, Perreira B, Brenner M, Ferrada P, et al. The Colombian Experience in Resuscitative Endovascular Balloon Occlusion of the Aorta (REBOA): The Progression from a Large Caliber to a Low-Profile Device at a Level I Trauma Center. Shock. 2020. Doi: 10.1097/SHK.0000000000001515.

26. Ribeiro Junior MAF, Feng CYD, Nguyen ATM, Rodrigues VC, Bechara GEK, de-Moura RR, et al. The complications associated with Resuscitative Endovascular Balloon Occlusion of the Aorta (REBOA). World J Emerg Surg 2018;13:20. Doi: 10.1186/s13017-018-0181-6.

27. Vrancken SM, Borger van der Burg BLS, Vrancken PJEM, Kock GAH, Rasmussen TE, Hoencamp R. A contemporary assessment of devices for Resuscitative Endovascular Balloon Occlusion of the Aorta (REBOA): resource-specific options per level of care. Eur J Trauma Emerg Surg 2020. Doi: 10.1007/s00068-020-01382-5.

28. Knipp BS, Needham KE, Nguyen PT, Keville MP, Brzuchalski JT, Srivilasa C, et al. Leaning Forward: Early Arterial Access Promotes REBOA Utilization in Battlefield Casualties. J Trauma Acute Care Surg. 2020; 89(2S Suppl 2):S88-S92 Doi: 10.1097/TA.0000000000002790.

29. Beyer CA, Johnson MA, Galante JM, DuBose JJ. Zones matter: Hemodynamic effects of zone 1 vs zone 3 resuscitative endovascular balloon occlusion of the aorta placement in trauma patients. Injury 2019;50:855-8. Doi: 10.1016/j.injury.2019.03.013.

30. Kuckelman JP, Barron M, Moe D, Derickson M, Phillips C, Kononchik J, et al. Extending the golden hour for Zone 1 resuscitative endovascular balloon occlusion of the aorta: Improved survival and reperfusion injury with intermittent versus continuous resuscitative endovascular balloon occlusion of the aorta of the aorta in a porcin. J Trauma Acute Care Surg 2018;85:318-26. Doi: 10.1097/TA.0000000000001964.

31. Bulger EM, Perina DG, Qasim Z, Beldowicz B, Brenner M, Guyette F, et al. Clinical use of resuscitative endovascular balloon occlusion of the aorta (REBOA) in civilian trauma systems in the USA, 2019: a joint statement from the American College of Surgeons Committee on Trauma, the American College of Emergency Physicians, the National Association of Emergency Medical Services Physicians and the National Association of Emergency Medical Technicians. Trauma Surg Acute Care Open 2019;4:e000376. Doi: 10.1136/ tsaco-2019-000376.

32. Sadeghi M, Hörer TM, Forsman D, Dogan EM, Jansson K, Kindler C, et al. Blood pressure targeting by partial REBOA is possible in severe hemorrhagic shock in pigs and produces less circulatory, metabolic and inflammatory sequelae than total REBOA. Injury 2018;49:2132-41. Doi: 10.1016/j.injury.2018.09.052. 